\title{
The Place of Community Rescue Naloxone in a Public Health Crisis of Opioid Overdose
}

\author{
Joseph V. Pergolizzi ${ }^{1,2}$, Jo Ann LeQuang3 ${ }^{3}$, Robert Taylor ${ }^{1}$, Robert B. Raffa ${ }^{2,4,5}$ (i) \\ ${ }^{1}$ NEMA Research, Naples, FL, USA \\ ${ }^{2}$ Neumentum, Palo Alto, CA, USA \\ ${ }^{3}$ LeQ Medical, Angleton, TX, USA \\ ${ }^{4}$ University of Arizona College of Pharmacy, Tucson, AZ, USA \\ ${ }^{5}$ Temple University School of Pharmacy, Philadelphia, PA, USA \\ Email: robert.raffa@temple.edu
}

How to cite this paper: Pergolizzi, J.V., LeQuang, J.A., Taylor, R. and Raffa, R.B. (2019) The Place of Community Rescue Naloxone in a Public Health Crisis of Opioid Overdose. Pharmacology \& Pharmacy, 10, 61-81.

https://doi.org/10.4236/pp.2019.102006

Received: November 13, 2018

Accepted: January 29, 2019

Published: February 1, 2019

Copyright $\odot 2019$ by author(s) and Scientific Research Publishing Inc. This work is licensed under the Creative Commons Attribution International License (CC BY 4.0).

http://creativecommons.org/licenses/by/4.0/

\begin{abstract}
The recent large increase in deaths involving opioids (whether prescription or illicit, pure or adulterated, alone or in combination with other drugs) is the manifestation of a complex, and multifaceted problem consisting of psychological, psychosocial, medical, legal, regulatory, economic, cultural, and political components, among others. Because the problem involves issues related to both supply and demand, the solution is not obvious, simple, or quick. There is no easy fix. Preventing and treating opioid misuse and abuse requires a comprehensive, time-intensive, and expensive intervention supported by public policy and support through coordinated medical, regulatory, legal, and financial guidelines and practice. But until the long-term problems can be fixed, the immediate crisis of overdose deaths can be ameliorated by making available an opioid receptor antagonist to reverse the respiratory depression that is the cause of death to those who are in the best position to administer it in time (professionals, untrained bystanders, and even fellow drug abusers). The statistics overwhelmingly demonstrate that this is a life-saving medical intervention. Yet, there is still uncertainty about this intervention, and even some opposition to it. We describe the scientific basis for the approach and the issues surrounding its use to treat accidental or intentional overdose by pain patients, recreational opioid users, and addicts. We also describe the calls to limit the number of times it should be available to a user and the limitations of its effectiveness-mainly that it only addresses the acute death crisis, not the underlying problems that led to it.
\end{abstract}

\section{Keywords}

Opioid Crisis, Opioid Abuse, Opioid Antagonist, Community Naloxone 


\section{Introduction}

At its peak, nearly 100 people died each day in the United States (US) from overdose associated with an opioid substance (prescription, or heroin and other illicitly manufactured substances of unknown purity). In 2016, opioids were involved in 42,249 overdose deaths (66.4\% of all drug overdose deaths) [1]. Mortality associated with overdose involving an opioid substance steadily increased every year [2], increasing 11.4\% between 2014 and 2015 alone [3]. Deaths associated with synthetic opioids other than methadone (such as illicit fentanyl) increased $72.2 \%$ from 2014 to 2015, and overdose deaths associated with natural or semisynthetic opioid products increased by $2.6 \%$ [3].

Figure 1 shows overdose deaths in the United States from 2000 to 2015 showing the sharp upsurge in deaths associated with heroin and synthetic opioids, which includes illicit fentanyl [1]. The data are collected for "synthetic opioids", which includes prescription fentanyl and tramadol as well as illicitly manufactured forms of fentanyl; most cases of harm associated with synthetic opioids involve illicit forms of fentanyl [4]. Using data from 27 states, the Centers for Disease Control and Prevention (CDC) determined that from 2013 to 2014, the number of fentanyl submissions increased by $426 \%$ and the number of overdose deaths from synthetic opioids increased $79 \%$ but these changes did not correlate with changes in fentanyl prescribing rates [5].

Naloxone is a $\mu$-opioid receptor antagonist which is approved for the treatment of an opioid emergency such as an overdose or a possible opioid overdose with signs of breathing problems and severe sleepiness or not being able to respond. Naloxone competes for the same receptor sites used by the opioid [6]. Antagonism by naloxone of agonist action is dose related and the dose of naloxone needed to reverse agonist-induced respiratory depression depends on the

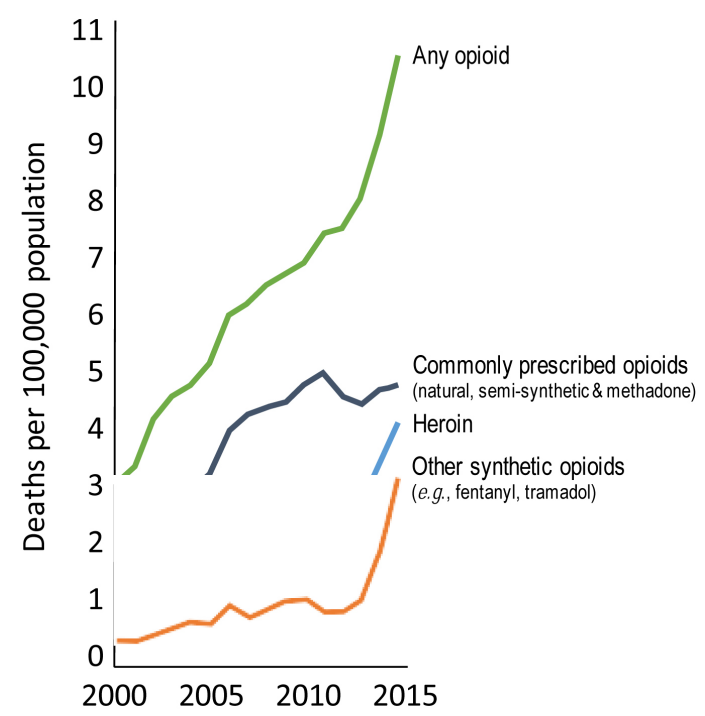

Figure 1. Overdose deaths in the United States from 2000 to 2015 showing the sharp upsurge in deaths associated with heroin and synthetic opioids, which includes illicit fentanyl. Data from [1]. 
particular agonist [6] [7] [8]. Prompt administration of an adequate dose of an antagonist is crucial. For this reason, community efforts are being explored to be able to administer naloxone quickly in the case of suspected overdose.

Naloxone is currently available in several formulations for different routes of administration with the Food and Drug Administration (FDA) approving doses of $4 \mathrm{mg} / 0.1 \mathrm{~mL}$ for the nasal spray and $0.4 \mathrm{mg} / 0.4 \mathrm{~mL}$ for intramuscular (IM) autoinjector formulation [9]. Naloxone has a rapid onset of action and, when administered soon enough, patient response occurs in seconds to minutes. Failure to administer sufficient naloxone rapidly enough may result in mortality due to respiratory depression. The effective dose of naloxone required to reverse opioid toxicity is affected by a number of factors, including the amount of opioid the subject has ingested [8]. In the US, most states have moved to allow individuals to obtain it without prescription and this has not been challenged by federal authorities [10], but administering the drug without proper training and credentials may expose an individual to legal consequences [11].

Community naloxone programs attempt to educate and equip laypeople to administer naloxone in cases of suspected opioid overdose and most states have passed laws to facilitate the administration of naloxone by laypeople in emergency situations, but these laws vary from state to state [12] [13] [14]. Pharmacists in particular are on the front lines and may have to educate patients about naloxone administration, signs of overdose, as well as provide guidance relating to the local Good Samaritan laws governing the administration of naloxone by laypeople [15].

In theory, laypersons may be able to administer naloxone more quickly than traditional emergency medical services (EMS) because they are on the scene, but it is not known if these individuals can be adequately trained and would be willing to administer the drug appropriately. Further, associated risks and outcomes from community naloxone efforts are not yet known. The purpose of our article is to offer a narrative review of community naloxone efforts and the associated concerns.

\section{Methods}

For this narrative review, we searched sources such as PuBMed and MedLine for articles in English language and the FDA and Centers for Disease Control and Prevention (CDC) websites for official commentary on community naloxone efforts. The authors conducted searches of the PubMed databases using terms community naloxone, naloxone effectiveness, and naloxone intervention. Bibliographies of relevant articles were also searched. Our goal was to identify and address key concerns about community naloxone programs.

\section{The Goals and Objectives of Community Naloxone Initiatives}

The goal of any community naloxone program is reduction of overdose morbid- 
ity and mortality; naloxone distribution programs do not address the root causes of opioid addiction [16]. Thus, community naloxone programs are at most a harm-reduction effort aimed at preventing opioid overdose mortality. Furthermore, community naloxone efforts typically exist in tandem with local or municipal services, such as EMS, which also provide naloxone for suspected opioid overdoses. The goal of community naloxone is not to replace municipal or emergency services in this regard, but to augment it and extend their reach.

That city services are already stretched with respect to opioid overdoses is quite clear. A city councilman in Middletown Ohio proposed that city services use naloxone to resuscitate individuals with opioid overdose no more than twice and that subsequent requests for emergency aid go unanswered [17]. While this was not a measure that the council enacted or even treated seriously, it speaks to the growing frustration of many cities in the US with respect to how opioid overdoses are treated-and how naloxone resuscitation is perceived. In this particular case, the use of naloxone was perceived as decreasing a potential drug user's fear of overdose, thus perpetuating and exacerbating the problem of opioid addiction rather than solve it. The Ohio news story received national coverage and while it sparked outrage, it also raised an important but frequently unmentioned concern. About $39 \%$ of opioid abusers $(n=440)$ who sought detoxification reported a history of opioid overdose and $25 \%$ reported at least one overdose episode in the past year [18]. Thus, many inidividuals rescued from potentially life-threatening opioid overdoses have had overdoses previously-and may continue to have more.

Naloxone has been used to reverse overdose toxicity in more than 10,000 cases since it was introduced in the US [19]. Since the opioid epidemic is also a major public health problem in other parts of the world [20], the US leading role in community naloxone efforts might have a global context.

The goal of community naloxone efforts is that people who may be likely to observe a suspected opioid overdose can be taught to identify the signs of opioid overdose and be trained and equipped to deliver an appropriate dose of naloxone quickly, as a bridge to care, and then summon medical help. In a meta-analysis of pooled data from four studies, naloxone administered by laypersons in the community was associated with a significantly increased rate of recovery when compared to no naloxone (odds ratio $8.58,95 \%$ confidence interval, 3.90 to 13.25$)$ [21].

\section{Dosing}

Naloxone dosing is empirical. The effective dose will depend on which, and how much, opioid the overdose victim has ingested, the relative affinity of naloxone for the $\mu$-opioid receptor and the amount of opioid to be displaced, the patient's weight, and the extent to which opioids have entered the person's central nervous system [22] [23]. In most emergency situations, this information is unavailable and cannot be readily ascertained. With naloxone products (nasal spray, 
autoinjector) the product's dose is preset. With improvised kits, it is recommended that dosing be repeated until the patient responds, up to a maximum dose [24]. It is thought that if a dose of $15 \mathrm{mg}$ does not reverse respiratory depression in a given patient, the cause of respiratory depression in not likely to be related to opioid overdose [24] [25]. In the absence of opioids, naloxone shows little to no pharmacologic activity [26].

The intranasal system and auto-injector dispense $0.4 \mathrm{mg}$ with no way to titrate up except to administer more doses, if available. The FDA advice on the approved naloxone dose for community use is $0.4 \mathrm{mg}$ naloxone for injections [9]. In the event that a single dose is insufficient to reverse opioid toxicity, a second or subsequent doses are recommended. The FDA has stated "there is no single effective dose [of naloxone] for all opioid overdoses" [9].

The effective dose of naloxone must take into account many factors, few of which may be known by the first responders encountering the overdose. For example, the effective naloxone dose may depend on the specific opioid(s) consumed, any other drug(s) consumed at the same time, the dose(s) of those drugs, the formulation(s) of those drugs, route of administration, and patient-related factors such as any underlying diseases (such as pulmonary dysfunction), level of opioid tolerance, and exogenous stimulatory factors [6] [8] [27].

In the community setting, the person administering the naloxone may be uncertain as to what drug(s) were taken, and if there are other complicating factors, such as chronic obstructive pulmonary disease to be considered. Indeed, the first responder may even be uncertain as to whether or not an opioid overdose has occurred or if the subject is unresponsive for some other reason. Even when a layperson knows what opioid(s) the subject has taken to overdose, it is unlikely he or she will be able to adjust naloxone dose based on these factors. In the community setting, the biggest risk for the community use of emergency naloxone is that too little naloxone will be administered too late.

\section{Risks}

If the overdose victim is opioid dependent, naloxone may cause the victim to experience withdrawal symptoms, which may be delayed or immediate [28]. Acute withdrawal symptoms (AWS) occur in chronic opioid users who have developed physical dependence on the opioids and is well described in the literature and known in clinical experience. AWS are distressing and unpleasant, but rarely fatal [8] [29] [30] [31]. In a prospective study from Europe in 1998 to 1999, investigators evaluated adverse events associated with 1192 overdose episodes in which subjects were treated with naloxone by EMS personnel [30]. About a third of these patients (33\%) experienced adverse events associated with withdrawal [30]. Typical symptoms of withdrawal include: agitation, yawning, rhinorrhea, lacrimation, piloerection, diaphoresis, myalgia, nausea, vomiting, and diarrhea [8] [31]. In a study of community naloxone administered to reverse suspected opioid overdoses, withdrawal symptoms were observed by $14.3 \%$ of 
those who administered naloxone, with the most commonly reported symptoms being nausea, vomiting, or gagging (10.2\%) or agitation and hostility (8.7\%) [32]. Withdrawal symptoms typically do not last more than 30 minutes to an hour because of the short half-life of naloxone [33].

High doses of naloxone, up to $90 \mathrm{mg} /$ day in IV boluses, have been administered to non-opioid-dependent individuals with no reported adverse effects [8]. However, naloxone may have cardiovascular adverse effects in individuals with a pre-existing heart condition. Other adverse effects may include confusion, restlessness, and agitation upon emergence, headache, and seizures (likely related to hypoxia) [30].

\section{Setting up Community Naloxone Programs}

Community naloxone programs rely on individuals who are likely to witness opioid overdose outside of the hospital and who are willing to be trained and equipped to administer naloxone in this emergency situation. This population includes friends and family members of those taking prescription opioids, friends and family members of known opioid abusers and addicts, and people who come in regular contact with the general public, such as those who work in schools, restaurants, public or government offices, businesses, and so on. These individuals must be trained in terms of how to identify signs of suspected opioid overdose and how to administer naloxone in an emergency. Implementing a program of this magnitude requires that healthcare professionals work with policymakers to provide naloxone and train community responders [16]. While community naloxone programs make good sense, there is only limited scientific evidence to date that they improve outcomes, because these programs are relatively new [16].

Some communities will train any volunteers to administer naloxone while other programs may recruit specific individuals based on criteria such as likelihood of witnessing an overdose or willingness to respond in an emergency [34]. Naloxone may be subsidized and thus provided free to responders [34] or it may be subsidized and then made available to trained responders at reduced costs [35]. In the US a greater than 10-fold increase in naloxone dispensing from retail pharmacies has been observed from the fourth quarter of 2013 and the second quarter of 2015 (Figure 2) [36].

\section{Overdose Demographics}

In setting up a community naloxone program, it is important to understand the population of potential opioid overdose victims. Individuals who are dependent on opioids are the most likely group to experience opioid overdose [16]. The risk for overdose is elevated for those who start using opioids after a period of abstinence, since tolerance to opioids decreases [37]. Thus, opioid abusers who are released from incarceration, treatment centers, detoxification programs, or who for whatever reason have stopped using opioids and then restarted are at elevated 


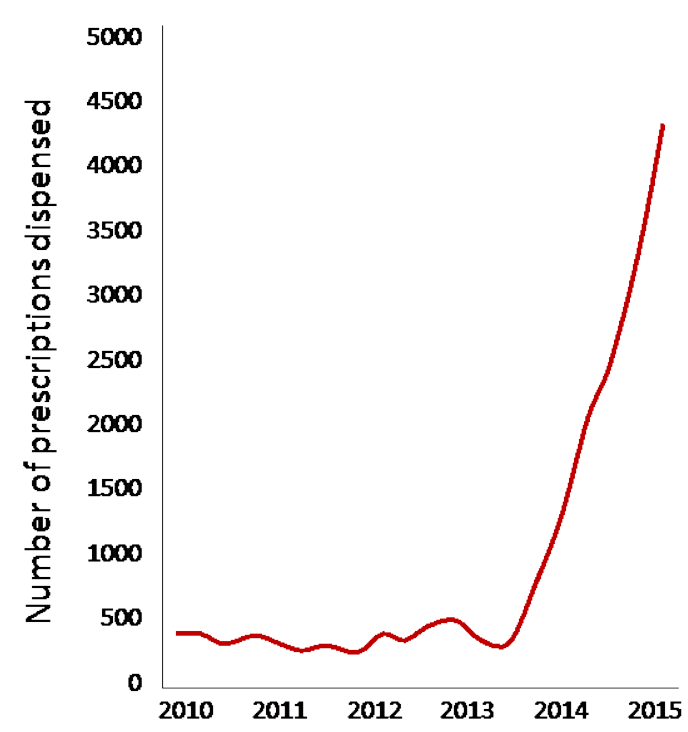

Figure 2. The sharp increase in naloxone prescriptions dispensed from retail pharmaciesduring 2010 to 2015 in the United States. Data from [36].

overdose risk [38] [39] [40] [41]. Users who take their opioid drugs intravenously are also at higher risk of overdose than are those who smoke opioids or take them by mouth [42] [43] [44] [45].

Patients taking prescribed opioids and individuals taking illicit opioids can overdose, but patients taking prescribed opioids under medical supervision are at lower risk. Among prescription opioid users under medical care, risks for overdose include higher dosage, male sex, older age, multiple prescriptions (including benzodiazepines), mental health disorders, and lower socioeconomic status [2] [46] [47] [48] [49] [50]. Patients under medical care often continued opioid therapy even after a nonfatal overdose. In a retrospective review of a commercial insurance database with data on more than 50 million patients, 2848 patients were identified who had been prescribed opioids for chronic pain between 2000 and 2012 and who had suffered a non-fatal overdose [51]. In this time span, $7 \%$ experienced a second opioid overdose and, within this subset, $70 \%$ continued to be prescribed opioids by the same prescriber after the overdose [51]. Overdose can be correlated to the opioid dose-the incidence of overdose in this study was $17 \%$ among patients who had been prescribed $\geq 100$ morphine equivalents per day versus $9 \%$ who had been prescribed $<50$ morphine equivalents per day. Further, the mean daily dose tended to increase rapidly in the week before overdose which suggests patients either experienced worsening pain or drug-seeking behavior or both [51]. In a similar retrospective study, the same conclusions could be drawn. It was found that $91 \%$ of patients who survived an overdose of prescription opioids continued to be prescribed opioids, often by the same prescriber(s) [52]. Risk factors for opioid overdose from both illicit opioids and prescription opioids include: middle age (40 to 49 years) [53] [54], less than high school education [55], recent prescription for sedative-hypnotics [49], and diagnosis of bipolar disorder and depression [56]. 
Drug overdose has been associated with depression and the use of antidepressants in depression (but not the use of antidepressants without depressions) [57]. People who had previously attempted suicide had a higher incidence of opioid overdose than others without this history [55] [58]. Overdose rates can also be correlated to sales trends for prescription opioids and opioid-related visits to the emergency department in a given region [59]. There is evidence that living in a rural and/or impoverished region of the country may itself be a risk factor for opioid overdose [60].

The type of opioid may also play a role in overdose incidence. A study from Australia found that heroin overdoses were three-fold more frequent than oxycodone overdoses (12.7 versus 4.1 per 1000 injections), and that heroin overdoses had more severe clinical symptoms [61]. In many parts of the world, illicit fentanyl and other so-called designer drugs are important factors in opioid toxicity. Fentanyl is a synthetic, highly selective, potent, lipophilic opioid originally developed for parenteral use only [62]. Its high first-pass metabolism makes it less suitable for development as an oral formulation, but transdermal and transmucosal formulations as well as injectables are approved and commercially available. Its predictable pharmacokinetics makes it a useful drug in a carefully controlled clinical setting [62]. Illicit fentanyl manufactured in clandestine labs is relatively inexpensive and easy to produce; increasingly, this cheaper illicit fentanyl is used to cut heroin or to be the active ingredient in counterfeit opioid tablets [63]. Since fentanyl is extremely potent, illicit fentanyl manufactured in makeshift labs by untrained people can be deadly even in very small amounts. Furthermore, drug users may ingest fentanyl unawares, thinking they are buying street heroin or even prescription oxycodone [63]. A grim example of this occurred in Connecticut in the summer of 2016 when 12 individuals presented at a New Haven emergency department; all had used what they believed to be illicit cocaine [64]. The "cocaine" was in fact fentanyl with only trace amounts of actual cocaine. Nine of the individuals were admitted to the hospital (four were admitted to intensive care); three needed endotracheal intubation and one required a continuous infusion of naloxone. Three of the 12 patients died. In a study from Massachusetts in collaboration with the CDC, about two-third of those who died from opioid overdoses from October 1, 2014 to March 31, 2015 tested positive on postmortem toxicology for fentanyl [65]. In a study of overdose victims who were rescued and subsequently interviewed, most attributed the overdose to a false assessment of drug purity (that is, drugs were stronger or cut with adulterants that the user was unaware of) or simply misfortune [58]. The "fentanyl epidemic" makes community naloxone programs all the more urgent, yet it makes dosing more problematic. In vitro studies indicate that naloxone is able to displace fentanyl at opioid receptors [66]. To better define opioid receptor occupancy with respect to type of opioid and dose of naloxone, healthy volunteers were studied with intravenous (IV) naloxone. Patients administered carfentanil (a chemical analog of fentanyl) $2 \mathrm{mg}$ IV achieved $81 \%$ occupancy of 
mu-opioid receptors $(\mathrm{n}=8)$ [67], while patients administered diprenorphine 1 mg IV achieved 50\% mu-opioid receptor occupancy $(n=5)$ [7]. A limitation of this study is that the tests were carried out in healthy individuals under controlled conditions with IV agents. Opioid-dependent individuals may have greater numbers of $\mu$-opioid receptors than opioid-naïve individuals, necessitating larger doses of naloxone for effective reversal [7] [27] Likewise, illicit fentanyl may require higher and more rapid naloxone exposure to reverse a potential overdose.

Polysubstance abuse increases the risk of overdose; from 2004 to 2008, 38\% of emergency room visits for overdose involved one drug while $62 \%$ involved polysubstance abuse [68]. In particular, the use of benzodiazepines and/or alcohol with opioids increases the risk of overdose [58]. Substance abuse in general can be correlated to opioid overdose [49], and the majority of patients in opioid rehabilitation or treatment programs report a previous overdose [58].

Other factors should also be considered in the context of elevated risk of overdose. For example, in a study of 218 discharged military veterans who reported using opioids in the past month, groups could be made consisting of subjects who were non-adherent and those who used heroin; both groups were further subdivided into "occasional" versus "regular" users [69]. Both groups of "regular" users were more likely to screen positive for alcohol and substance abuse, reported using opioids to relieve anxiety, reported higher levels of physical pain, were more likely to have mental health issues, were more likely to have been in drug or alcohol rehabilitation programs, and were less likely to be employed or in school. Furthermore, regular heroin users were less likely to have a stable domicile [69].

Some individuals experience multiple overdoses, in that not all overdoses are fatal. In a retrospective study of opioid overdoses, there were seven nonfatal overdose cases for every fatal overdose (in this study, $12 \%$ of patients experienced a fatal overdose) [70].

\subsection{Naloxone Knowledge among Persons Who Use Drugs}

The Injection Drug Users Health Alliance Citywide Study (IDUCS) is the largest study to date of persons who use drugs (PWUDs) participating in harm reduction programs in the US. From 2014 to 2015, 2421 individuals who took part in 14 local harm reduction programs in New York City were surveyed [71]. It was found that younger PWUDs were more likely to report a recent overdose than older PWUDs but younger PWUDs were less likely to know about naloxone and its role in reversing overdose [71]. In a series of in-depth semi-structured interviews with 46 young people (ages 18 to 32) in New York who abused prescription opioids, participants were not well informed about the use of naloxone. Many of these participants viewed themselves as distinct from IV heroin users and, as such, were often excluded in harm reduction programs [72]. These respondents believed that prescription opioids were far less dangerous than heroin 
in terms of risking overdose. Most participants had either witnessed an overdose or known someone who had suffered a nonfatal overdose, but few knew (or did not know well) signs of overdose, appropriate steps to take, or the role of rescue naloxone [72].

\subsection{Community Responders}

While friends, family, and authority figures who might witness an overdose are considered good candidates to administer naloxone in community outreach programs, many programs rely on PWUDs. This population is very likely to observe an overdose. In a systematic review of the literature, it was found that among drug users, $50 \%$ to $96 \%$ would witness a drug overdose in their lifetime (mean 73\%, median 70\%); lifetime prevalence of drug users personally experiencing a nonfatal overdose was $16.6 \%$ to $68 \%$ (mean $45 \%$, median $47 \%$ ) [73]. There is evidence that PWUDs are willing and able to administer naloxone after training. A systematic review of nine studies of community naloxone programs found a range of 5.2 to 13.1 uses of naloxone every three months for every 100 PWUDs trained [74]. Among PWUDs, about 9\% of naloxone kits were used within three months [74].

Qualitative interviews with 35 heroin addicts who had witnessed at least one overdose were conducted in a study in Sweden [75]. Overall, the addicts had a positive attitude about assisting others who might have overdosed, but there were notable barriers. In some cases, the observer was already high and may not notice the overdose or, if noticing the symptoms, may underestimate the seriousness of the situation [75]. Some addicts stated that they did not want to interfere with another person's experience ("high") or might recognize an overdose but be unsure if it was intentional-and in that case, not wish to intrude [75]. Addicts were sometimes unsure if the overdose victim wanted help, which contributed to their occasional reticence about administering naloxone. Fear of law enforcement was stated as a potential barrier to naloxone administration, but was not a primary factor [75].

In addition to occasional ambivalence about administering naloxone to another drug user, some drug users were unwilling to summon emergency help. In a study of 101 active heroin users in Albuquerque from January 7 to February 26,2002 , there were 95 witnessed heroin overdoses ( 80 of which were witnessed by three or more persons) [76]. The observers in this study did not have naloxone and so could not render aid themselves. Emergency help was summoned in $44 \%$ of these witnessed overdoses, although nearly all (100/101) said they would have been willing to administer naloxone if it were available. The main reason these observers said they had not summoned medical help for overdose victims was a fear of police involvement [76]. In a study of 973 intravenous heroin users in San Francisco under age 30, 73\% had witnessed at least one heroin overdose; $50 \%$ had witnessed a heroin overdose that year, of which $14 \%$ had a fatal outcome [77]. Again, observers did not have naloxone and so could not provide 
rescue. Emergency help was summoned in about half of the witnessed overdoses (52\%) [77]. In instances where emergency services were not called, the two most common reasons given by witnesses were because the overdose victim regained consciousness (67\%) and because they feared police involvement (18\%) [77].

\section{Medical Help Following Overdose Rescue}

An important but largely unresolved question deals with whether or not the overdose victim receives medical care following successful resuscitation. In the clinical setting, patients treated with naloxone would be routinely subjected to at least a brief period of observation, and in the absence of consensus guidelines, Boyer suggests this monitoring period ought to last about four or five hours [31]. Individuals rescued with naloxone from a community member or by EMS may refuse transport to a hospital for observation or, indeed, may refuse emergency medical services altogether. In a retrospective review of data over five years from out-of-hospital and medical examiner databases, investigators examined all cases in which opioid overdose was listed as a contributing factor to the death; these cases were then cross-compared to those who received naloxone delivered by emergency personnel and who refused transport to a hospital [78]. This study evaluated 998 out-of-hospital patients who were administered emergency naloxone for suspected overdose and refused transport or further treatment. In this same time period, this community had 601 opioid overdose deaths, but there was no overlap, that is, no emergency-treated naloxone patient who refused further treatment subsequently died of an opioid overdose [78]. In a US study with a similar objective, 592 patients treated with rescue naloxone for a suspected overdose refused transport to the emergency department while 40 accepted transport to the hospital for observation and possibly further treatment [79]. None of the patients who were reversed with naloxone but refused further treatment died within the first study endpoint (two days); one death occurred at four days and nine died within 30 days [79]. However, none of these deaths occurred in direct association with the naloxone administration and refusal to go to the hospital. In a qualitative study based on semi-structured interviews in Denver, most laypeople who were able to administer naloxone and reverse an overdose did not call emergency medical services. The most frequent reasons for not getting medical help was fear of police response or fear that alerting the authorities might result in other penalties, such as certain individuals who thought it might jeopardize their public housing or other benefits [80]. A literature review about outcomes in heroin overdose victims who are reversed with naloxone but refuse transportation to the emergency room found very low risk of death providing there were no co-intoxicants used and the patient was left with normal vital signs and mentation [81]. Willman et al. recommended that overdose patients treated with naloxone in the hospital setting be observed for an hour and be discharged upon good ambulation, normal vital signs, and a Glasgow Coma Scale score of 15 [81]. 
As the half-life of naloxone is much shorter than the half-life of many opioids, such as heroin, revived patients may experience "rebound toxicity" as the naloxone wears off [16]. The WHO suggests that the first responder ought to remain with the overdose victim until the naloxone has worn off to be sure the patient maintains consciousness and can still breathe effectively [16]. Overdose victims who relapse following the initial naloxone administration may be given more naloxone [16].

\section{Effectiveness of Naloxone}

Naloxone is an effective treatment for opioid overdose. In a study of eight first-responder or community organizations that provided data on the use of naloxone to treat suspected cases of overdose, successful reversals were reported in $98.8 \%$ of cases $(242 / 245)$ and $73.5 \%$ of successful revivals occurred within five minutes or less (Figure 3) [32]. In a retrospective study of 154 patients administered naloxone by trained emergency personnel, clinical response for those who got naloxone intranasally (IN) was $66 \%(n=104)$ compared to $56 \%$ for those who received intravenous (IV) naloxone $(\mathrm{n}=50)$. Clinical response was defined in this study as increased respiratory rate (breaths/min) or a Glasgow Coma Scale score $\geq 6$. The mean time between naloxone administration and signs of clinical response was significantly longer for the IN group (12.9 vs. 8.1 minutes, $\mathrm{p}=0.02$ ) but the mean times from patient contact to clinical response did not differ significantly (20.3 vs. 20.7 minutes, $\mathrm{p}=0.9$ ). This suggests that IN naloxone is a viable real-world alternative to IV naloxone and is appropriate for the community setting, where securing proper IV access would often be a barrier to naloxone administration. More IN than IV patients required two doses (34\% vs. $18 \%, \mathrm{p}=0.05)[82]$.

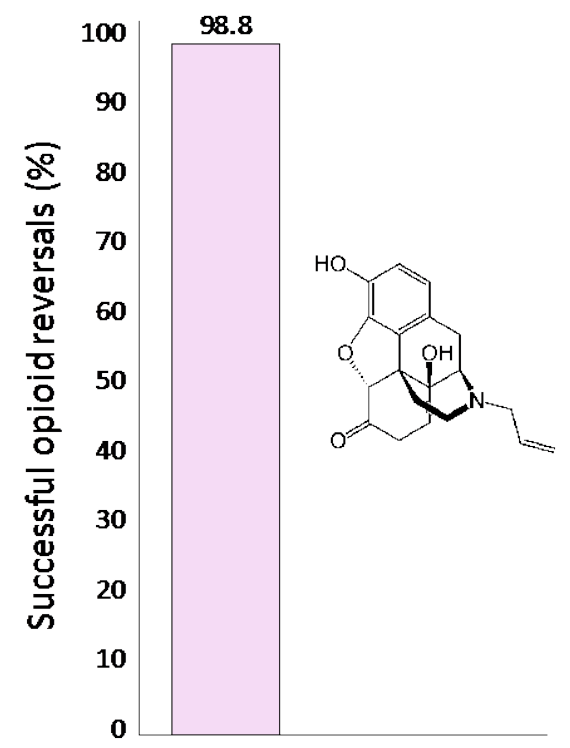

Figure 3. Opioid overdose reversal by naloxone (structure inset) (242 of 245 cases). Data from [32]. 


\section{Discussion}

Community naloxone outreach and "take-home" naloxone are important innovations as harm reduction measures for the opioid epidemic. The emergence of illicit fentanyl and analogs as designer drugs is particularly concerning and makes the role of community naloxone efforts all the more urgent. Illicit fentanyl (and analogs) is emerging as the most dangerous group of new drugs associated with overdose toxicity [5]; so prevalent is its use that the DEA has named illicit fentanyl one of the key drivers of the current opioid epidemic [83]. Fentanyl, both prescription and illicit forms, is highly potent, such that a very small amount can be potentially lethal [84]. To make matters worse, illicit fentanyl is relatively inexpensive, such that clandestine drug manufacturers may stretch a supply of a given drug, such as heroin, by cutting it with cheaper illicit fentanyl [5]. This adulteration is not necessarily disclosed to the buyers, so those who take illicit drugs or heroin may be consuming potentially dangerous amounts of fentanyl without knowing it. Furthermore, some drug dealers are producing counterfeit pills that look like pharmaceutical-grade opioids; these pills are made with fillers and illicit fentanyl, but they are sold to abusers as prescription pain relievers [83]. Fentanyl is a highly lipophilic substance [85] and in vitro models have shown that naloxone, likewise lipophilic, can effectively displace fentanyl effectively from opioid receptors [7]. However, rapid administration of adequate doses of naloxone is required to revive a subject from fentanyl overdose.

Community naloxone programs require several important foundations for success. First, it is important to be able to both train and equip the first responders tasked with administering naloxone in emergency situations. These individuals must be trained to identify signs of possible opioid overdose. Further, these community responders must be willing to administer naloxone in these situations and summon emergency medical services. Many people who are likely to witness opioid overdoses and who would be willing to render aid are not necessarily skilled in identifying opioid overdose or how to administer naloxone. The emergence of easy-to-use IN naloxone spray and a naloxone autoinjector are helpful, but many community naloxone programs will still rely on improvised kits for cost reasons. Thus, it is crucial that efforts be made to educate and equip first responders.

The legal impediments need to be clarified and, if appropriate, removed. Communities should be sure that so-called "Good Samaritan" laws are in place that protects individuals who render aid in good faith. There may also be regulations with respect to how naloxone may be distributed within the community. In some parts of the country, naloxone requires a prescription but can still be obtained without one-that sort of murky status should be addressed. Pharmacists, in particular, are on the frontlines and need to know local laws and how to advise community members about the use of naloxone.

Data are still lacking in terms of the extent to which community naloxone outreaches improve outcomes, but naloxone is highly effective in reversing 
opioid overdose. The challenges remain in that naloxone is expensive in terms of time, money, and resources to administer and it may be that certain individuals overdose repeatedly, taxing the goodwill and economic reserve of their local communities. Thus, community naloxone programs should be incorporated into a broader, overarching opioid program that includes education for prescribers, training for other clinicians and law enforcement agents, and treatment options for opioid addicts. Naloxone dosing is empirical and while certain guidance appears in the literature and from the FDA, in the community setting it is likely that naloxone will be administered repeatedly until the patient responds or until a dose of $15 \mathrm{mg}$ is reached. Since the adverse effects associated with naloxone appear to be manageable, this is perhaps a reasonable solution to emergency field care. An initial dose of $0.4 \mathrm{mg}$ of naloxone is recommended, but in the age of fentanyl and even more potent opioids such as carfentanil and polysubstance abuse by hard-core drug users, this dose is likely inadequate for some overdose victims.

Community naloxone programs have an important place in modern societies where opioid use and abuse is prevalent. The WHO has set forth guidelines as to how to set up and run such a program. It is important that physicians and other healthcare providers, insurers, the legal system, regulators, and taxpayers support these life-saving efforts.

The US population is prescribed significantly more opioids per capita than is any other developed country. As a negative consequence, it is unfortunately more experienced with the associated problem of overdose deaths. However, the US experience having to deal with this problem might serve as a guide to other countries. At the near opposite end of opioid use is the economically comparative country Japan. Japan has had historically low prescribing of opioids and a low abuse problem. However, opioid use in Japan is on the rise (Figure 4) [86]. Because of the lack of experience dealing with this issue, healthcare providers in Japan feel uncertainty, and have low confidence in their abilities to deal with it

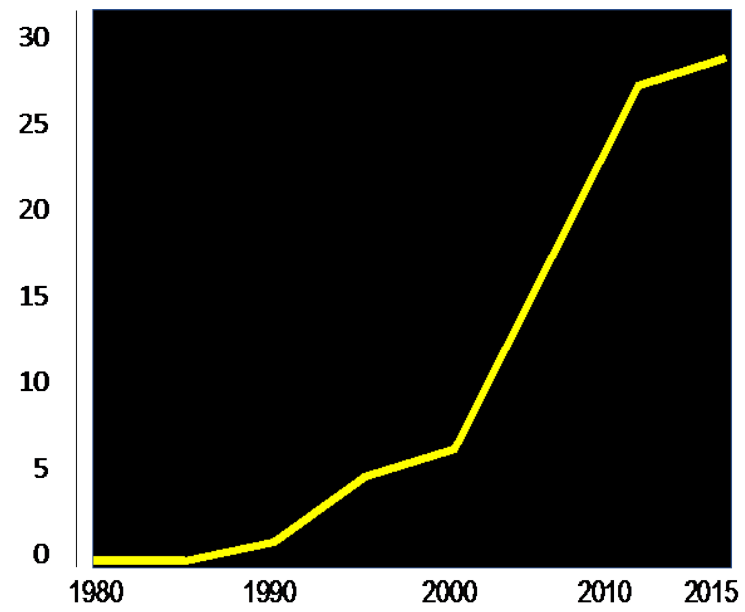

Figure 4. Annual per-capital opioid consumption in Japan (mg morphine equivalents). Data from [86]. 
[87]. The experience with community naloxone in the US could serve as a valuable resource for other countries such as Japan dealing with the rising problem.

\section{Conclusion}

Promptly administered at sufficient doses following an opioid overdose, naloxone is highly effective at reversing respiratory depression associated with opioid overdose. In light of the public health crisis of opioid-related morbidity and mortality, the role of community responders in administering naloxone is evolving and expanding. A variety of naloxone products are available, ranging from intramuscular naloxone to prepackaged kits (one for intranasal administration, the other for injection) and improvised kits using a syringe and mucosal atomizer. The dosing of naloxone is empirical and higher doses may be needed to reverse the respiratory depression associated with certain potent illicit opioids, such as fentanyl analogs (e.g. carfentanil, sufentanyl, alfentanyl).

\section{Acknowledgements}

The authors thank John Bisney for editorial assistance.

\section{Conflicts of Interest}

The authors declare no conflicts of interest regarding the publication of this paper.

\section{References}

[1] CDC (2018) Drug Overdose Death Data. https://www.cdc.gov/drugoverdose/data/statedeaths.html

[2] CDC (2011) Overdoses of Prescription Opioid Pain Relievers-United States, 1999-2008. Morb Mortal Wkly Report, 60, 1487-1492.

https://www.cdc.gov/mmwr/preview/mmwrhtml $/ \mathrm{mm6043a4.htm?s \_ cid=mm6043a}$ $\underline{4 \_\mathrm{W}}$

[3] Rudd, R., Seth, P., David, F. and Scholl, L. (2016) Increases in Drug and Opioid-Involved Overdose Deaths-United States 2010-2015. Morb Mortal Wkly Report, 65, 1445-1452. https://www.cdc.gov/mmwr/volumes/65/wr/mm655051e1.htm https://doi.org/10.15585/mmwr.mm655051e1

[4] CDC (2018). https://www.cdc.gov/drugoverdose/data/otherdrugs.html

[5] Gladden, R.M., Martinez, P. and Seth, P. (2016) Fentanyl Law Enforcement Submissions and Increases in Synthetic Opioid-Involved Overdose Deaths-27 States, 2013-2014. Morb Mortal Wkly Report, 65, 837-843. https://www.cdc.gov/mmwr/volumes/65/wr/mm6533a2.htm https://doi.org/10.15585/mmwr.mm6533a2

[6] Dahan, A., Aarts, L. and Smith, T. (2010) Incidence, Reversal, and Prevention of Opioid-Induced Respiratory Depression. Anesthesiology, 112, 226-238. https://doi.org/10.1097/ALN.0b013e3181c38c25

[7] Melichar, J.K., Nutt, D.J. and Malizia, A.L. (2003) Naloxone Displacement at Opioid Receptor Sites Measured in Vivo in the Human Brain. European Journal of Pharmacology, 459, 217-219. https://doi.org/10.1016/S0014-2999(02)02872-8 
[8] Clarke, S., Dargan, P. and Jones, A. (2005) Naloxone in Opioid Poisoning: Walking the Tightrope. Emergency Medicine Journal, 22, 612-616.

[9] FDA (2016) FDA Advisory Committe on the Most Appropriate Dose or Doses of Naloxone to Reverse the Effects of Life-Threatening Opioid Overdose in the Community Settings. Vol. 2017, Rockville, MD.

https://www.fda.gov/downloads/advisorycommittees/committeesmeetingmaterials/ drugs/anestheticandanalgesicdrugproductsadvisorycommittee/ucm522688.pdf

[10] Alcorn, T. (2014) America Embraces Treatment for Opioid Drug Overdose. The Lancet, 383, 1957-1958. https://doi.org/10.1016/S0140-6736(14)60928-4

[11] Evolutions (2017) Which States Offer Naloxone over the Counter? https://cvshealth.com/thought-leadership/naloxone-opioid-overdose-reversal-medi cation

[12] Davis, C.S. and Carr, D. (2015) Legal Changes to Increase Access to Naloxone for Opioid Overdose Reversal in the United States. Drug and Alcohol Dependence, 157, 112-120. https://doi.org/10.1016/j.drugalcdep.2015.10.013

[13] Davis, C. and Carr, D. (2017) State Legal Innovations to Encourage Naloxone Dispensing. Journal of the American Pharmaceutical Association, 57, S180-S184. https://doi.org/10.1016/j.japh.2016.11.007

[14] Brodrick, J.E., Brodrick, C.K. and Adinoff, B. (2016) Legal Regimes Surrounding Naloxone Access: Considerations for Prescribers. The American Journal of Drug and Alcohol Abuse, 42, 117-128. https://doi.org/10.3109/00952990.2015.1109648

[15] Weaver, L., Palombi, L. and Bastianelli, K.M. (2017) Naloxone Administration for Opioid Overdose Reversal in the Prehospital Setting: Implications for Pharmacists. Journal of Pharmacy Practice, 31, 91-98. https://doi.org/10.1177/0897190017702304

[16] WHO (2014) Community Management of Opioid Overdose. http://apps.who.int/iris/bitstream/handle/10665/137462/9789241548816_eng.pdf;jse ssionid=F0223501860DF35AA622874D9094C8ED? sequence $=1$

[17] Bacon, J. (2017) Ohio Councilman: After 2 Overdoses, No More EMS. USA Today, New York.

https://www.usatoday.com/story/news/nation/2017/06/28/ohio-councilman-suggest s-three-strikes-law-halt-overdose-rescues/434920001/

[18] Stein, M.D., Flori, J.N., Risi, M.M., Conti, M.T., Anderson B.J. and Bailey, G.L. (2017) Overdose History Is Associated with Post-Detoxification Treatment Preference for Persons with Opioid Use Disorder. Substance Abuse, 38, 389-393. https://doi.org/10.1080/08897077.2017.1353570

[19] Wheeler, E. (2012) Community-Based Opioid Overdose Prevention Programs Providing Naloxone. Morbidity and Mortality Weekly Report, 61, 101-105. https://www.cdc.gov/mmwr/preview/mmwrhtml/mm6106a1.htm

[20] Mostaghim, R. and Bengali, S. (2016) Iran's Growing Drug Problem: "No Walk of Society is Immune". Los Angeles Times, Los Angeles. http://www.latimes.com/world/la-fg-iran-drug-addiction-2016-story.html

[21] Giglio, R.E., Li, G. and DiMaggio, C.J. (2015) Effectiveness of Bystander Naloxone Administration and Overdose Education Programs: A Meta-Analysis. Injury Epidemiology, 2, 10. https://doi.org/10.1186/s40621-015-0041-8

[22] Tenenbein, M. (1984) Continuous Naloxone Infusion for Opiate Posioning in Infancy. Journal of Pediatrics, 105, 645-648. https://doi.org/10.1016/S0022-3476(84)80440-0

[23] Berkowitz, B. (1976) The Relationship of Pharmacokinetics to Pharmacological Ac- 
tivity: Morphine, Methadline and Naloxone. Clinical Pharmacokinetics, 1, 219-230. https://doi.org/10.2165/00003088-197601030-00004

[24] Schumann, H., Erickson, T., Thompson, T., Zautcke, J. and Denton, J. (2008) Fentanyl Epidemic in Chicago, Illinois and Surrounding Cook Country. Clinical Toxicology, 46, 501-506. https://doi.org/10.1080/15563650701877374

[25] Prosser, J., Jones, B. and Nelson, L. (2010) Complications of Oral Exposure to Fentanyl Transdermal Delivery System Patches. Journal of Medical Toxicology, 6, 443-447. https://doi.org/10.1007/s13181-010-0092-8

[26] Kim, D., Irwin,K. and Khoshnood, K. (2009) Expanded Access to Naloxone: Options for Critical Response to the Epidemic of Opioid Overdose Mortality. American Public Health Association, 99, 402-407. https://doi.org/10.2105/AJPH.2008.136937

[27] Kim, H.K. and Nelson, L.S. (2015) Reducing the Harm of Opioid Overdose with the Safe Use of Naloxone: A Pharmacologic Review. Expert Opinion on Drug Safety, 14, 1137-1146. https://doi.org/10.1517/14740338.2015.1037274

[28] Drugs.com. (2018) Naloxone. https://www.drugs.com/monograph/naloxone-hydrochloride.html

[29] Wermeling, D.P. (2015) Review of Naloxone Safety for Opioid Overdose: Practical Considerations for New Technology and Expanded Public Access. Therapeutic Advances in Drug Safety, 6, 20-31. https://doi.org/10.1177/2042098614564776

[30] Buajordet, I., Naess, A.C., Jacobsen, D. and Brors, O. (2004) Adverse Events after Naloxone Treatment of Episodes of Suspected Acute Opioid Overdose. European Journal of Emergency Medicine, 11, 19-23. https://doi.org/10.1097/00063110-200402000-00004

[31] Boyer, E.W. (2012) Management of Opioid Analgesic Overdose. New England Journal of Medicine, 367, 146-155. https://doi.org/10.1056/NEJMra1202561

[32] Avetian, G.K., Fiuty, P., Mazzella, S., Koppa, D., Heye, V. and Hebbar, P. (2017) Use of Naloxone Nasal Spray $4 \mathrm{mg}$ in the Community Setting: A Survey of Use by Community Organizations. Current Medical Research and Opinion, 34, 573-576. https://doi.org/10.1080/03007995.2017.1334637

[33] Dowling, J., Isbister, G.K., Kirkpatrick, C.M., Naidoo, D. and Graudins, A. (2008) Population Pharmacokinetics of Intravenous, Intramuscular, and Intranasal $\mathrm{Na}$ loxone in Human Volunteers. Therapeutic Drug Monitoring, 30, 490-496. https://doi.org/10.1097/FTD.0b013e3181816214

[34] Arthurs S. (2017) Community-Wide Naloxone Training Planned Monday. The Courier, Findlay.

https://thecourier.com/local-news/2017/04/20/community-wide-naloxone-trainingplanned-monday/

[35] Targeted News Service (2017) Virginia Receives \$9.7 Million Grant to Fight Opioid Crisis. Newsbank Inc., Richmond.

https://www.governor.virginia.gov/newsroom/all-releases/2018/may/headline-8254 99-en.html

[36] Jones, C.M., Lurie, P.G. and Compton, W.M. (2016) Increase in Naloxone Prescriptions Dispensed in US Retail Pharmacies since 2013. American Public Health Association, 106, 689-690. https://doi.org/10.2105/AJPH.2016.303062

[37] Donoghoe, M. (1999) Opioid Overdose: An International Perspective. Addiction, 94, 1745-1746. https://doi.org/10.1046/j.1360-0443.1999.9411174511.x

[38] Binswanger, I.A., Blatchford, P.J., Mueller, S.R. and Stern, M.F. (2013) Mortality af- 
ter Prison Release: Opioid Overdose and Other Causes of Death, Risk Factors, and Time Trends from 1999 to 2009. American College of Physicians, 159, 592-600. https://doi.org/10.7326/0003-4819-159-9-201311050-00005

[39] Krinsky, C.S., Lathrop, S.L., Brown, P. and Nolte, K.B. (2009) Drugs, Detention, and Death: A Study of the Mortality of Recently Released Prisoners. American Journal of Forensic Medicine and Pathology, 30, 6-9. https://doi.org/10.1097/PAF.0b013e3181873784

[40] Davoli, M., Bargagli, A.M., Perucci, C.A., et al. (2007) Risk of Fatal Overdose during and after Specialist Drug Treatment: The VEdeTTE Study, a National Multi-Site Prospective Cohort Study. Addiction, 102, 1954-1959. https://doi.org/10.1111/j.1360-0443.2007.02025.x

[41] Cornish, R., Macleod, J., Strang, J., Vickerman, P. and Hickman, M. (2010) Risk of Death during and after Opiate Substitution Treatment in Primary Care: Prospective Observational Study in UK General Practice Research Database. BMJ, 341, c5475. https://doi.org/10.1136/bmj.c5475

[42] Darke, S., Williamson, A., Ross, J., Mills, K.L., Havard, A. and Teesson, M. (2007) Patterns of Nonfatal Heroin Overdose over a 3-Year Period: Findings from the Australian Treatment Outcome Study. Journal of Urban Health, 84, 283-291. https://doi.org/10.1007/s11524-006-9156-0

[43] Bennett, T., Holloway, K. and Bird, S.M. (2014) Does Take-Home Naloxone Reduce Non-Fatal Overdose? The Lancet, 383, 124-125. https://doi.org/10.1016/S0140-6736(14)60022-2

[44] Gossop, M., Griffiths, P., Powis, B., Williamson, S. and Strang, J. (1996) Frequency of Non-Fatal Heroin Overdose: Survey of Heroin Users Recruited in Non-Clinical Settings. BMJ, 313, 402. https://doi.org/10.1136/bmj.313.7054.402

[45] Brugal, M.T., Barrio, G., De, L.F., Regidor, E., Royuela, L. and Suelves, J.M. (2002) Factors Associated with Non-Fatal Heroin Overdose: Assessing the Effect of Frequency and Route of Heroin Administration. Addiction, 97, 319-327. https://doi.org/10.1046/j.1360-0443.2002.00058.x

[46] Park, T.W., Lin, L.A., Hosanagar, A., Kogowski, A., Paige, K. and Bohnert, A.S. (2016) Understanding Risk Factors for Opioid Overdose in Clinical Populations to Inform Treatment and Policy. Journal of Addiction Medicine, 10, 369-381. https://doi.org/10.1097/ADM.0000000000000245

[47] Darke, S., Kaye, S. and Duflou, J. (2006) Systemic Disease among Cases of Fatal Opioid Toxicity. Addiction, 101, 1299-1305.

https://doi.org/10.1111/j.1360-0443.2006.01495.x

[48] Bohnert, A.S., Valenstein, M., Bair, M.J., et al. (2011) Association between Opioid Prescribing Patterns and Opioid Overdose-Related Deaths. JAMA, 305, 1315-1321. https://doi.org/10.1001/jama.2011.370

[49] Dunn, K.M., Saunders, K.W., Rutter, C.M., et al. (2010) Opioid Prescriptions for Chronic Pain and Overdose: A Cohort Study. American College of Physicians, 152, 85-92. https://doi.org/10.7326/0003-4819-152-2-201001190-00006

[50] Hall, A.J., Logan, J.E., Toblin, R.L., et al. (2008) Patterns of Abuse among Unintentional Pharmaceutical Overdose Fatalities. JAMA, 300, 2613-2620. https://doi.org/10.1001/jama.2008.802

[51] Wise, J. (2016) Most US Patients Continue to Be Prescribed Opioids after Overdose. BMJ, 352, h7010. https://doi.org/10.1136/bmj.i701

[52] Gregg, J. (2016) Follow-Up to Nonfatal Opioid Overdoses: More of the Same or an 
Opportunity for Change? American College of Physicians, 164, 62-63. https://doi.org/10.7326/M15-2687

[53] Unick, G.J., Rosenblum, D., Mars, S. and Ciccarone, D. (2013) Intertwined Epidemics: National Demographic Trends in Hospitalizations for Heroin- and Opioid-Related Overdoses, 1993-2009. PLoS ONE, 8, e54496. https://doi.org/10.1371/journal.pone.0054496

[54] Fulton-Kehoe, D., Garg, R.K. and Turner, J.A., et al. (2013) Opioid Poisonings and Opioid Adverse Effects in Workers in Washington State. American Journal of Industrial Medicine, 56, 1452-1462. https://doi.org/10.1002/ajim.22266

[55] Bonar, E.E., Ilgen, M.A., Walton, M. and Bohnert, A.S. (2014) Associations among Pain, Non-Medical Prescription Opioid Use, and Drug Overdose History. American Journal on Addictions, 23, 41-47. https://doi.org/10.1111/j.1521-0391.2013.12055.x

[56] Yoon, Y.H., Chen, C.M., Yi, H.Y. and Moss, H.B. (2011) Effect of Comorbid Alcohol and Drug Use Disorders on Premature Death among Unipolar and Bipolar Disorder Decedents in the United States, 1999 to 2006. Comprehensive Psychiatry, 52, 453-464. https://doi.org/10.1016/j.comppsych.2010.10.005

[57] Turner, B.J. and Liang, Y. (2015) Drug Overdose in a Retrospective Cohort with Non-Cancer Pain Treated with Opioids, Antidepressants, and/or Sedative-Hypnotics: Interactions with Mental Health Disorders. Journal of General Internal Medicine, 30, 1081-1096. https://doi.org/10.1007/s11606-015-3199-4

[58] Man, L.H., Best, D., Gossop, M., Stillwell, G. and Strang, J. (2004) Relationship between Prescribing and Risk of Opiate Overdose among Drug Users in and Out of Maintenance Treatment. European Addiction Research, 10, 35-40. https://doi.org/10.1159/000073724

[59] Modarai, F., Mack, K., Hicks, P., et al. (2013) Relationship of Opioid Prescription Sales and Overdoses, North Carolina. Drug and Alcohol Dependence, 132, 81-86. https://doi.org/10.1016/j.drugalcdep.2013.01.006

[60] Bunn, T.L., Yu, L., Spiller, H.A. and Singleton, M. (2010) Surveillance of Methadone-Related Poisonings in Kentucky Using Multiple Data Sources. Pharmacoepidemiol Drug Safety, 19, 124-131. https://doi.org/10.1002/pds.1901

[61] Roxburgh, A., Darke, S., Salmon, A.M., Dobbins, T. and Jauncey, M. (2017) Frequency and Severity of Non-Fatal Opioid Overdoses among Clients Attending the Sydney Medically Supervised Injecting Centre. Drug and Alcohol Dependence, 176, 126-132. https://doi.org/10.1016/j.drugalcdep.2017.02.027

[62] Schug, S.A. and Ting, S. (2017) Fentanyl Formulations in the Management of Pain: An Update. Drugs, 77, 747-763. https://doi.org/10.1007/s40265-017-0727-Z

[63] Frank, R. and Pollack, H. (2017) Addressing the Fentanyl Threat to Public Health. $J A M A, 376,605-607$.

[64] Tomassoni, A.J., Hawk, K.F., Jubanyik, K., et al. (2017) Multiple Fentanyl Overdoses-New Haven, Connecticut, June 23, 2016. Morbidity and Mortality Weekly Report, 66, 107-111. https://www.cdc.gov/mmwr/volumes/66/wr/mm6604a4.htm https://doi.org/10.15585/mm6604a4

[65] Somerville, N.J., O’Donnell, J., Gladden R.M., et al. (2017) Characteristics of Fentanyl Overdose-Massachusetts, 2014-2016. Morbidity and Mortality Weekly Report, 66, 382-386. https://www.cdc.gov/mmwr/volumes/66/wr/mm6614a2.htm https://doi.org/10.15585/mmwr.mm6614a2

[66] Villiger, J.W., Ray, L.J. and Taylor, K.M. (1983) Characteristics of $\left[{ }^{3} \mathrm{H}\right]$ Fentanyl Binding to the Opiate Receptor. Neuropharmacology, 22, 447-452. 
https://doi.org/10.1016/0028-3908(83)90162-4

[67] Kim, S., Wagner Jr., H.N., Villemagne, V.L., et al. (1997) Longer Occupancy of Opioid Receptors by Nalmefene Compared to Naloxone as Measured in Vivo by a Dual-Detector System. Journal of Nuclear Medicine, 38, 1726-1731.

[68] Centers for Disease C, Prevention (2010) Emergency Department Visits Involving Nonmedical Use of Selected Prescription Drugs-United States, 2004-2008. Morbidity and Mortality Weekly Report, 59, 705-709. https://www.cdc.gov/mmwr/preview/mmwrhtml/mm5923a1.htm

[69] Bennett, A.S., Golub, A. and Elliott, L. (2017) A Behavioral Typology of Opioid Overdose Risk Behaviors among Recent Veterans in New York City. PLoS ONE, 12, e0179054. https://doi.org/10.1371/journal.pone.0179054

[70] Elzey, M.J., Barden, S.M. and Edwards, E.S. (2016) Patient Characteristics and Outcomes in Unintentional, Non-Fatal Prescription Opioid Overdoses: A Systematic Review. Pain Physician, 19, 215-228.

[71] Calvo, M., MacFarlane, J., Zaccaro, H., et al. (2017) Young People Who Use Drugs Engaged in Harm Reduction Programs in New York City: Overdose and Other Risks. Drug and Alcohol Dependence, 178, 106-114.

https://doi.org/10.1016/j.drugalcdep.2017.04.032

[72] Frank, D., Mateu-Gelabert, P., Guarino, H., et al. (2015) High Risk and Little Knowledge: Overdose Experiences and Knowledge among Young Adult Nonmedical Prescription Opioid Users. International Journal of Drug Policy, 26, 84-91. https://doi.org/10.1016/j.drugpo.2014.07.013

[73] Martins, S.S., Sampson, L., Cerda, M. and Galea, S. (2015) Worldwide Prevalence and Trends in Unintentional Drug Overdose: A Systematic Review of the Literature. American Public Health Association, 105, e29-e49. https://doi.org/10.2105/AJPH.2015.302843

[74] McAuley, A., Aucott, L. and Matheson, C. (2015) Exploring the Life-Saving Potential of Naloxone: A Systematic Review and Descriptive Meta-Analysis of Take Home Naloxone (THN) Programmes for Opioid Users. International Journal of Drug Policy, 26, 1183-1188. https://doi.org/10.1016/j.drugpo.2015.09.011

[75] Richert, T. (2015) Wasted, Overdosed, or beyond Saving-To Act or Not to Act? Heroin Users' Views, Assessments, and Responses to Witnessed Overdoses in Malmo, Sweden. International Journal of Drug Policy, 26, 92-99. https://doi.org/10.1016/j.drugpo.2014.07.006

[76] Baca, C.T. and Grant, K.J. (2007) What Heroin Users Tell Us about Overdose. Journal of Addictive Diseases, 26, 63-68. https://doi.org/10.1300/J069v26n04_08

[77] Davidson, P.J., Ochoa, K.C., Hahn, J.A., Evans, J.L. and Moss, A.R. (2002) Witnessing Heroin-Related Overdoses: The Experiences of Young Injectors in San Francisco. Addiction, 97, 1511-1516. https://doi.org/10.1046/j.1360-0443.2002.00210.x

[78] Vilke, G.M., Sloane, C., Smith, A.M. and Chan, T.C. (2003) Assessment for Deaths in Out-Of-Hospital Heroin Overdose Patients Treated with Naloxone Who Refuse Transport. Academic Emergency Medicine, 10, 893-896. https://doi.org/10.1197/aemj.10.8.893

[79] Wampler, D.A., Molina, D.K., McManus, J., Laws, P. and Manifold, C.A. (2011) No Deaths Associated with Patient Refusal of Transport after Naloxone-Reversed Opioid Overdose. Prehospital Emergency Care, 15, 320-324. https://doi.org/10.3109/10903127.2011.569854

[80] Koester, S., Mueller, S.R., Raville, L., Langegger, S. and Binswanger, I.A. (2017) Why 
Are Some People Who Have Received Overdose Education and Naloxone Reticent to Call Emergency Medical Services in the Event of Overdose? International Journal of Drug Policy, 48, 115-124. https://doi.org/10.1016/j.drugpo.2017.06.008

[81] Willman, M.W., Liss, D.B., Schwarz, E.S. and Mullins, M.E. (2017) Do Heroin Overdose Patients Require Observation after Receiving Naloxone? Clinical Toxicology, 55, 81-87. https://doi.org/10.1080/15563650.2016.1253846

[82] Robertson, T.M., Hendey, G.W., Stroh, G., and Shalit, M. (2009) Intranasal Naloxone Is a Viable Alternative to Intravenous Naloxone for Prehospital Narcotic Overdose. Prehospital Emergency Care, 13, 512-515. https://doi.org/10.1080/10903120903144866

[83] DEA (2016) 2016 National Drug Threat Assessment. https://www.dea.gov/documents/2017/10/01/2017-national-drug-threat-assessment

[84] Sutter, M.E., Gerona, R.R., Davis, M.T., et al. (2016) Fatal Fentanyl: One Pill Can Kill. Academic Emergency Medicine, 24, 106-113. https://doi.org/10.1111/acem.13034

[85] Volpe, D.A., McMahon Tobin, G.A., Mellon, R.D., et al. (2011) Uniform Assessment and Ranking of Opioid Mu Receptor Binding Constants for Selected Opioid Drugs. Regulatory Toxicology and Pharmacology, 59, 385-390. https://doi.org/10.1016/j.yrtph.2010.12.007

[86] University of Wisconsin Pain \& Policy Studies Group (2018). http://www.painpolicy.wisc.edu/country/profile/japan

[87] Shimane, T., Matsumoto, T. and Wada, K. (2015) Clinical Behavior of Japanese Community Pharmacists for Preventing Prescription Drug Overdose. Psychiatry and Clinical Neurosciences, 69, 220-227. https://doi.org/10.1111/pcn.12232 